\title{
OS ESTÁGIOS IDENTITÁRIOS DA ENFERMEIRA-GERENTE: UMA ABORDAGEM PIAGETIANA ${ }^{1}$ THE IDENTITY CONSTRUCTION STAGES OF NURSE MANAGERS: A PIAGETIAN APPROACH LAS ETAPAS EN LA CONSTRUCCIÓN DE LA IDENTIDAD DE LA ENFERMERA EN EL ÁREA DE LA GERENCIA SEGÚN EL ABORDAJE DE PIAGET
}

\author{
Maria José Menezes Brito², Maria Flávia Carvalho Gazzinelli’3, Marlene Catarina de Oliveira Lopes Melo
}

\begin{abstract}
${ }^{1}$ Este artigo foi elaborado a partir da tese de Brito "A configuração identitária da enfermeira no contexto das práticas de gestão em hospitais privados de Belo Horizonte", apresentada ao Programa de Pós-Graduação em Administração da Faculdade de Ciências Econômicas da Universidade Federal de Minas Gerais (UFMG), em 2004. Área de concentração: Relações de Poder e de Trabalho.

${ }^{2}$ Enfermeira. Doutora em Administração. Professora Adjunto da Escola de Enfermagem da UFMG.

${ }^{3}$ Bióloga. Doutora em Educação. Professora Adjunto da Escola de Enfermagem da UFMG.

${ }^{4}$ Jornalista. Doutora em Administração. Diretora acadêmica da Faculdade Novos Horizontes. Professora Titular aposentada da UFMG.
\end{abstract}

PALAVRAS-CHAVE: Conhecimento. Gerência. Crise de identidade.

RESUMO: Propõe-se a compreender o processo de construção da identidade das enfermeiras no exercício da gerência em hospitais privados de Belo Horizonte, a partir de um paralelo com o processo de construção do conhecimento segundo Jean Piaget. Sabe-se que a identidade humana não é dada, constrói-se na infância e ao longo da vida, com a ajuda do outro. O indivíduo constitui suas estruturas cognitivas por meio de um processo organizado de adaptação, ampliando e aprimorando as estruturas mentais e da inteligência. Por meio de entrevistas semi-estruturadas e pelo recurso do teste projetivo gráfico identificou-se que o processo de construção da identidade das enfermeiras reflete singularidades da sua vivência e diferentes fases de maturidade em relação ao exercício da gerência. Tal processo, bem como a elaboração do conhecimento inclui três estágios: a crise de identidade ou conflito cognitivo; a fase de transição ou adaptação (assimilação e acomodação) e a fase de equilíbrio.

KEYWORDS: Knowledge. Management. Identity crisis.

PALABRAS CLAVE: Conocimiento. Gerencia. Crisis de identidad.
ABSTRACT: This study proposes to assess the nurses' comprehension of their identity construction process as managers in Belo Horizonte's private hospitals. This is done from a parallel with the theoretical concepts of Jean Piaget, in which human identity is constructed during childhood and throughout life with other people's help. From this epistemological point of view, we know that the individual is not born with their cognitive structure. It is constructed by an organized process of adaptation that improves and refines mental structures and intelligence. Utilizing the semi-structured interviews and a projective graphic test, we identified that the identity construction process of the nurse managers reflects the singularity of their life and different phases of maturity related to management. We observe that identity construction and knowledge elaboration includes three stages: the identity crises or cognitive conflict; the transition phase or the adaptation (assimilation and accommodation); and the phase of equilibrium.

RESUMEN: Se propone comprender el proceso de construcción de la identidad de las enfermeras en el ejercicio de la gerencia en los hospitales privados de Belo Horizonte, a partir de un paralelo con el proceso de construcción del conocimiento según Jean Piaget. Se sabe que la identidad humana no es dada, sino esta se construye en la infancia y a largo de la vida, con la ayuda del otro. El individuo constituye sus estructuras cognitivas por medio de un proceso organizado de adaptación, ampliando y perfeccionando las estructuras mentales y las de la inteligencia. Por medio de las entrevistas semi estructuradas y por el recurso de la pruesa proyectiva gráfica se identificó que el proceso de construcción de la identidad de las enfermeras refleja singularidades de su vivencia y de sus diferentes fases de madurez con relación al ejercicio de la gerencia. Tal proceso, asi e como, la elaboración del conocimiento, abarca tres etapas: la crisis de identidad o conflicto cognitivo; la fase de transición o adaptación (asimilación y acomodación) y la fase del equilibrio.
Endereço: Maria José Menezes Brito

R. Prof. José Renault, 277, Ap. 503

30.350-760 - São Bento, Belo Horizonte, MG.

E-mail: brito@enf.ufmg.br
Artigo original: Pesquisa

Recebido em: 21 de novembro de 2005. Aprovação final: 04 de maio de 2006. 


\section{INTRODUÇÃO}

A relevância da temática e a complexidade que envolve o conceito de "identidade" são consenso entre alguns autores. ${ }^{1-4} \mathrm{~A}$ esse respeito ressalta-se a diversidade do emprego popular da palavra, sua amplitude conceitual, bem como as dificuldades de definição nos diferentes campos do conhecimento. ${ }^{3}$ Merece destaque a concepção de identidade como "uma expressão subjetiva que diz respeito a tudo aquilo que é vivenciado como eu, em resposta à pergunta 'quem és' podendo ser apreendida por meio da representação de si mesmo". 3:159

Variações na concepção e na valorização dos estudos sobre identidade podem ser observadas ao longo dos tempos. Assim a identidade é situada como foco de análise na psicologia social, voltando a ser discutida no interacionismo simbólico. ${ }^{5,6}$ Também são encontradas pesquisas sobre a identidade no campo da psicologia analítica do Eu e na Psicologia Cognitiva, as quais caracterizam seu desenvolvimento por meio de crescentes estágios de autonomia, tratando a identidade como um produto da socialização e assegurada pela individualização.

No que tange à constituição da identidade, ressalta-se a perspectiva de alguns estudiosos no sentido de que a identidade humana não é dada integralmente no ato do nascimento, mas "constrói-se na infância e deve reconstruir-se sempre ao longo da vida. $\mathrm{O}$ indivíduo nunca a constrói sozinho: ela depende tanto dos julgamentos dos outros como das suas próprias orientações e autodefinições, o que configura a identidade como um produto de sucessivas socializações." ${ }^{113} \mathrm{~A}$ proposta analítica acerca da identidade, no campo sociológico, sustenta-se na discussão da socialização como forma de construção das identidades sociais e profissionais, não havendo distinção entre identidade individual e identidade coletiva. ${ }^{1}$ Assim, a identidade social é fruto da articulação entre as transações 'interna' ao indivíduo e a transação 'externa' estabelecida entre o indivíduo e as instituições com as quais interage". $1: 103$

Também é interessante destacar que a proposta analítica apoiada nos processos culturais, discutidos nas vertentes antropológica e funcionalista da socialização e nas estratégias de ordem econômica defende a socialização como incorporação do babitus. ${ }^{1}$ Nesta perspectiva considera-se a identidade biográfica e relacional como elementos fundamentais na construção das identidades sociais. ${ }^{1}$ Essas categorias, destinadas à identificação dos outros e de si próprio, variam conforme os espaços nos quais se dão as interações sociais.

O processo identitário biográfico é definido "como uma construção no tempo a partir das categorias oferecidas pelas instituições sucessivas (família, escola, mercado de trabalho, empresa...)".:118 Chamase aqui atenção para a construção das categorias sociais com base nos campos escolar e profissional. O processo relacional, por sua vez, diz respeito ao reconhecimento, num dado momento, "[...] de legitimação das identidades associadas aos saberes, competências e imagens de si propostas e expressas pelos indivíduos nos sistemas de ação". 1:118 Assim, são evidenciadas as relações de trabalho, nas quais o indivíduo participa de atividades coletivas, no âmbito da organização e intervém no jogo de atores.

Além da análise do processo identitário biográfico e do processo identitário relacional, há que se considerar as esferas do trabalho e da formação como domínios pertinentes das identificações sociais. ${ }^{7}$ " $\mathrm{Na}$ esfera da formação do indivíduo, a identidade é reafirmada como algo em construção e, portanto, inacabado, reforçando a necessidade de que se compreenda não somente as 'identidades' mas também suas 'eventuais fraturas". $1: 105$ como produtos de uma tensão inerente ao próprio mundo social e nunca, prioritariamente, como resultados do funcionamento psíquico e dos seus recalcamentos biográficos.

A formação dos indivíduos se dá por meio da cognição entendida como conjunto de processos intelectuais e mentais que lhes permitem a apreensão do mundo, considerando os aspectos sócio-afetivos e culturais aí envolvidos. A idéia que se tem do mundo origina-se da cognição. $\mathrm{O}$ indivíduo não nasce com suas estruturas cognitivas, mas as constitui por um processo organizado de adaptação, de modo que no seu desenvolvimento, assimila o que provém do exterior (age sobre o objeto), acomoda este conhecimento (ajeita a ação do objeto sobre suas estruturas), torna a assimilar e acomodar em um movimento contínuo, que cria e recria os esquemas, estabelece relações entre os mesmos, ampliando e aprimorando, cada vez mais, as estruturas mentais e da inteligência.

Do ponto de vista epistemológico, a formação do indivíduo é sustentada na interação entre sujeito e objeto. Conhecer não consiste em copiar o real mas em agir sobre ele e transformá-lo (na aparência ou na realidade). Todo sujeito possui estruturas cognitivas e estruturas afetivas constituídas de esquemas cognitivos e esquemas emocionais. Esquemas constituem a princi- 
pal fonte dos conceitos e são eles que possibilitam a adaptação do sujeito ao meio, a qual se dá através de seus mecanismos constituintes: a assimilação e a acomodação. ${ }^{8}$

Desde o início, as estruturas mentais oferecem suporte tanto à formação quanto ao funcionamento dos esquemas. Assim, as estruturas são modificadas pelos novos esquemas, ou seja, se reestruturam, em um movimento permanente, dinâmico e dialético que se traduz na formação e desenvolvimento dos indivíduos. Correlacionar as etapas da elaboração da matriz de identidade social e profissional com as fases de desenvolvimento e construção do conhecimento, buscando uma compreensão mais global do processo de construção de identidade do indivíduo constitui, com efeito, objetivo deste artigo. ${ }^{9}$ A partir de um paralelo com o processo de elaboração de estruturas de apreensão do mundo e da realidade, este estudo pode contribuir para a compreensão de como se dá a dinâmica que constrói e mantém determinadas configurações identitárias de uma categoria profissional: a da enfermeira-gerente.

A construção da identidade correlaciona-se de forma direta com o ato de cuidar, constituindo um desafio para a enfermeira no exercício da gerência uma vez que este profissional vem ampliando seu espaço de atuação em organizações com novas configurações e arranjos estruturais. Considerando-se a identidade como sendo construída ao longo da trajetória de vida e fruto de relações sociais, da formação profissional e da inserção no mercado de trabalho, estudos dessa natureza se mostram relevantes por permitirem a elucidação da formação e desenvolvimento das enfermeiras-gerente. Ressalta-se, ainda, que a gestão constitui importante instrumento na viabilização do cuidado. Assim, modelos de gestão inovadores, descentralizados e direcionados para a valorização do trabalho em equipe possibilitam rupturas com os modelos tradicionais, com as fronteiras disciplinares e com as práticas hegemônicas. Nessa perspectiva, é reforçada a necessidade de estudos que busquem a compreensão de aspectos ligados ao corpo gerencial que vem assumindo a direcionalidade das práticas cuidativas na saúde e, portanto, favorecendo as ações de integralidade e a responsabilização dos diferentes atores sociais.

\section{PERCURSO METODOLÓGICO}

Com vistas a alcançar os objetivos propostos para este estudo, optou-se pela utilização de entrevistas semiestruturadas e pelo recurso do teste projetivo gráfico com enfermeiras no exercício da gerência no contexto de hospitais privados de Belo Horizonte. ${ }^{10-12}$

Em relação aos aspectos éticos da pesquisa, anteriormente à fase de coleta de dados o trabalho foi submetido ao Comitê de Ética em Pesquisa da Universidade Federal de Minas Gerais (UFMG) para apreciação e aprovação. Os sujeitos da pesquisa foram esclarecidos quanto aos objetivos do estudo, tendo sido assegurado o sigilo das informações e o anonimato dos sujeitos pesquisados. Para tanto, foi obtido o consentimento livre e esclarecido assinado.

O recurso do desenho projetivo foi utilizado de forma individual e imediatamente após a realização de entrevista, o que permitiu que as enfermeiras refletissem sobre as práticas gerenciais na enfermagem, reforçando e enriquecendo os aspectos subjetivos relacionados à sua identidade social e profissional. Sobre o recurso do desenho projetivo ressalta-se que o mesmo vem sendo utilizado por diversos pesquisadores com vistas à captação de aspectos subjetivos que possam subsidiar e enriquecer a percepção dos sujeitos da pesquisa. ${ }^{12-15} \mathrm{Tal}$ recurso tem contribuído para que as pessoas articulem sentimentos implícitos e de difícil resolução. ${ }^{13}$

A solicitação do desenho se deu mediante a seguinte pergunta: "expresse, por meio de um desenho, a sua percepção sobre o trabalho da enfermeira no exercício da função gerencial". Após a realização do desenho as enfermeiras foram requisitadas a explicarem sua representação. Tal explicação foi gravada na integra e contribuiu decisivamente para a fase de análise, a qual se deu por meio da realização de oficinas de especialistas com a participação de profissionais das áreas de psicologia, administração e letras e consistiu das seguintes etapas, a saber: 1) distribuição de cópia do desenho de cada gerente aos membros do grupo; 2) análise individual de cada membro do grupo com as devidas anotações e comentários no próprio desenho; 3) exposição por parte de cada um dos membros do grupo a respeito de sua percepção sobre o desenho; 4) discussão entre os membros do grupo; 5) leitura das explicações dadas pelas gerentes no ato da confecção dos desenhos; 6) rediscussão por parte do grupo e síntese.

As entrevistas foram submetidas à análise de conteúdo, utilizando instrumentos de tabulação e análise temática. ${ }^{10,11,16,17} \mathrm{O}$ processo de análise contemplou as fases de preparação e categorização temática. As entrevistas foram transcritas e organizadas de forma a permitir uma etapa preliminar de organização 
temática. A tabulação quantitativa foi realizada com a identificação de componentes das respostas das entrevistadas.

A segunda fase, de categorização propriamente dita, consistiu de leituras repetitivas das entrevistas em sua totalidade e, em seguida a organização de uma planilha de análise conforme os temas relevantes expressos pelos atores sociais. Deu-se, então, destaque à dimensão do dito ou da fala da enfermeira-gerente. Não se pretendeu apenas considerar a vivência do sujeito, por meio do seu discurso, como ponto de partida para a aplicação de teorias explicativas, mas de considerá-lo, também, como objeto teórico e de estudar, simultaneamente, os diversos componentes de referência dessa experiência das entrevistadas.

Por meio da análise observou-se que o processo de construção da identidade das enfermeiras refletiu singularidades da sua vivência e diferentes fases de maturidade em relação ao exercício da função gerencial. As referidas fases serão apresentadas no tópico a seguir.

\section{AS FASES IDENTITÁRIAS DA ENFER- MEIRA-GERENTE: A CONSTATAÇÃO DO "ETERNO VIR A SER"}

O processo de construção de identidade inclui três diferentes estágios, quais sejam, a crise de identidade; a fase de transição ou de elaboração da identidade; e a fase de equilíbrio ou de estabilidade.

\section{Crise de identidade: conflitos e fragilidades da enfermeira-gerente}

A crise de identidade é uma importante situação representada pelas gerentes, tendo sido expressa por G1 (Figura 1) e marcada pelo fato de a imagem da enfermeira assistencial se sobressair em relação à da gerente.

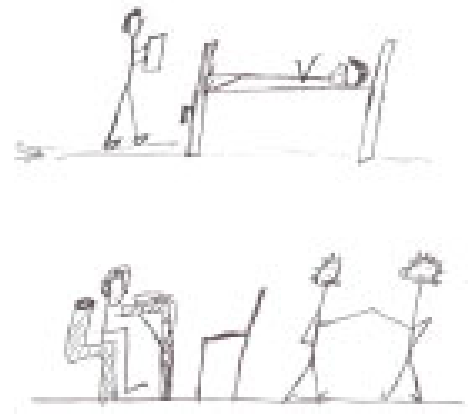

Figura 1 - Representação de G1 sobre o exercício da função gerencial.

A fase expressa pela gerente reflete a dicotomia que perpassa o gerenciar e o assistir e, portanto, a difi- culdade da enfermeira em perceber o processo de trabalho em saúde de forma integrada e totalitária. Desta forma, percebe-se que, para (G1), a visão do trabalho gerencial parece estar ligada à burocracia. As relações interpessoais no espaço de trabalho são expressas e refletem o distanciamento entre a gerente e a equipe de trabalho. A crise de identidade expressa por G1 pode ser evidenciada também em alguns trechos de seu depoimento, conforme ilustrado: algumas pessoas me dizem que eu deixei de ser enfermeira. E eu acho que é bem por ai. Você passa a ter o seu foco voltado para as questões administrativas, como contas, auditoria [...] e isso te consome! Você deixa de ser enfermeira e passa a ter outra profissão e a sua formação deixa de existir. Então você não é mais enfermeira (G1).

A respeito da "crise das identidades", destaca-se que sua existência decorre do movimento e dinâmica de "desestruturação/reestruturação" das identidades. Assim, “[...] cada configuração identitária tem hoje uma forma mista no interior da qual as antigas identidades entram em conflito com as novas exigências da produção e onde as antigas lógicas que perduram entram em combinação e, por vezes, em conflito com as novas tentativas de racionalização econômica e social. São estas formas mistas de permanência e de evolução, do antigo e do novo, do estável que se tornou ameaçante e do instável que se tornou valorizante, que são evidenciadas pelas análises empíricas cada vez mais numerosas que insistem tanto na permanência como na mudança!". 1:239

A assertiva do autor reflete o contexto de trabalho da enfermeira no exercício da gerência, exigindo novos posicionamentos, posturas e habilidades em face das atuais demandas da organização, de maiores exigências por parte da clientela e, ainda, em função de tecnologias inovadoras adotadas de forma muito específica no setor saúde e, principalmente na rede hospitalar. Dessa maneira, os atores sociais envolvidos nos processos produtivos são forçados a constantes adaptações, as quais são vivenciadas de formas diversas pelos referidos atores.

No processo de conhecimento, os esquemas mentais estão, a todo tempo, sendo estimulados, entrando em conflito e sofrendo desestruturações no contato com o meio. $\mathrm{Na}$ sua relação com o ambiente físico e social os indivíduos permanentemente sofrem com as "perturbações cognitivas" as quais promovem a desequilibração dos esquemas conceituais que, por sua vez, desestabilizam as estruturas mentais. ${ }^{8}$ Analogamente ao que acontece com as configurações identitárias, os conhecimentos de fora, do exterior, 
entram em conflito (perturbação conflitiva) com os que estão presentes nos esquemas mentais, uma vez que o processo de conhecer envolve de maneira invariante, o lidar com o novo, o diferente e mesmo com os limites de cada um.

Para que esta perturbação gere uma resposta, dentro de uma realidade conflitiva, ela não pode ser além e, muito menos, aquém das capacidades e conhecimentos dos indivíduos marcados pela sua singularidade. A esse respeito, fala-se do "quantum perturbativo", dosagem exata necessária para que a perturbação seja reconhecida como tal. ${ }^{8} \mathrm{O}$ fato das incitações do ambiente exterior não guardarem nenhum parentesco com o que o indivíduo conhece, faz com que ele se sinta tentado, cognitivamente falando, ao invés de reconhecer a perturbação em si, a reconhecêla como um simples desvio ou erro a ser corrigido.

Esta perspectiva abre possibilidades para analisar a dificuldade encontrada pela maioria dos indivíduos no tocante ao contato com o novo e à produção do conhecimento. Esse contato, importante lembrar, demanda sempre a suportabilidade da pessoa, já que ele pode fragilizar a estabilidade cognitiva de cada um, ou até mesmo, ameaçar a sua estabilidade identitária. Assim, do mesmo modo que ocorre com a crise de identidade nos indivíduos, o momento de conflito em termos cognitivos se constitui como um processo capaz de deslocar as estruturas e esquemas conceituais, incidindo sobre os quadros de referência que conferem aos indivíduos uma ancoragem estável na relação com os ambientes físico e social.

O novo, o estranho, o diferente, o não familiar, pode representar cognitivamente a dificuldade de ascensão a um conhecimento mais elaborado e, no processo de formação do indivíduo, o medo da perda da representação identitária. Este modo de funcionar pode ser encontrado em indivíduos que, em determinados momentos, para vencerem os obstáculos epistemológicos que os impedem de chegar ao conhecimento elaborado, necessitam negar, discriminar, desqualificar suas idéias prévias, sobretudo nas subjetividades marcadas por uma representação identitária extremamente rígida. Assim, quando o que está em voga é o ato de conhecer ou o de superação de uma crise identitária, espera-se que o indivíduo chegue a um estágio em que ele tenha condições subjetivas para questionar suas certezas, podendo reconhecer e sustentar o contato com o outro, interno e externo, sem sentir-se demasiadamente ameaçado.

\section{Transição: percorrendo um novo caminho}

A fase de transição pode ser observada nos desenhos e depoimentos de parte significativa do grupo de gerentes pesquisadas e reflete a fase por que vêm passando os hospitais e o exercício da gerência nos novos cenários organizacionais. Nessa ótica, chamase a atenção para algumas expressões subjetivas do grupo, como por exemplo, G2, as quais deixam transparecer a presença de uma construção sistematizada da atividade gerencial, bem como da profissional gerente, o que parece refletir a fase de elaboração de sua identidade profissional.

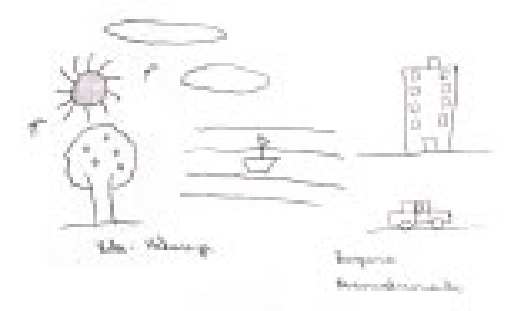

Figura 2A - Representação de G2 sobre o exercício da função gerencial.

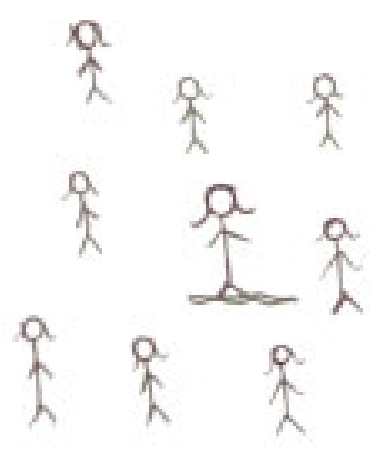

Figura 2B - Representação de G2 sobre o exercício da função gerencial.

A expressão de símbolos da natureza (sol, barco, água) sinaliza para uma certa tranqüilidade da entrevistada e reflete a passagem de uma vivência relativamente isenta de crise (Figura 2A). A atividade gerencial encontra-se em consonância com o cuidado direto ao paciente, ainda que seja prestado por outros membros da equipe de enfermagem, conforme ilustrado: en sou responsável pela viabilização das atividades de prestação do cuidado direto ao paciente. O trabalho da gerente é fundamental para que tudo chegue no paciente da melhor maneira (G2). 
Com relação ao desenvolvimento cognitivo, os indivíduos, nesta fase, buscam gerir os conflitos ou contradições surgidas. Tem início o processo segundo o qual o indivíduo tenta coordenar ou combinar os diferentes esquemas que possui em resposta às perturbações ocorridas. Essa situação é claramente notada na seqüência da representação da gerente com a elaboração de outro desenho (Figura $2 \mathrm{~B}$ ), por meio do qual a mesma abre espaço para a manifestação da estruturação do papel gerencial, uma vez que está situada no centro de um grupo ou de uma equipe.

Em termos da experiência com o saber, os indivíduos parecem sentir o conflito se preparando para enfrentá-lo. Assim, começam a progredir na medida em que se conscientizam da perturbação e experimentam superá-la. A assimilação é a incorporação de um elemento exterior num esquema conceitual do sujeito, englobando desde o começo, no mecanismo da repetição, "o elemento essencial pelo qual a atividade se distingue do hábito passivo: esse elemento é a coordenação entre o novo e o antigo, que anuncia o início do processo de julgamento. Com efeito, a reprodução própria do ato de assimilação implica sempre a incorporação de um dado atual a um determinado esquema, sendo esse esquema constituído pela própria repetição" 9:52

A acomodação é definida como a necessidade do esquema de assimilação em considerar as particularidades próprias dos elementos a assimilar. ${ }^{9}$ Decorre daí, que os esquemas conceituais e estruturas mentais do indivíduo são modificados de modo a acomodar os novos conhecimentos. Em outras palavras, abrem-se brechas nas estruturas mentais antes constituídas por um continuum cognitivo e afetivo. Assim, para que haja, de fato, adaptação é preciso um processo de autêntica construção. Diferentemente, a fase de transição identitária observada no desenho de G4 revela certa fragilidade em relação à própria gerente e ao grupo de trabalho.

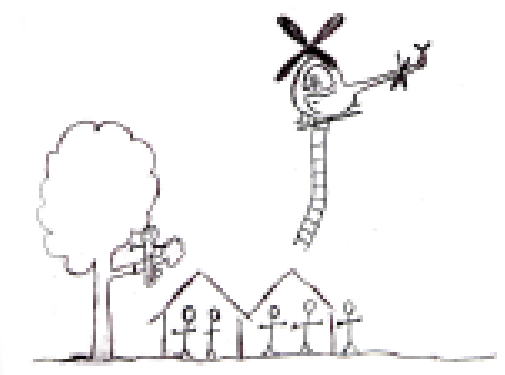

Figura 3 - Representação de G4 sobre o exercício da função gerencial.
No que diz respeito aos sentimentos acerca de si própria, a gerente parece utilizar a escada como forma de realizar uma escalada frágil e difícil, projetando uma situação de insegurança e de consciência da complexidade da atividade gerencial, insinuando, ainda, a possibilidade de fuga em face das dificuldades vivenciadas. Dessa forma, percebe-se que a despeito de os resultados de suas práticas gerenciais ainda não atenderem às suas expectativas, ela se coloca numa posição superior, a qual oferece a possibilidade de uma visão sistêmica da organização. Em relação à equipe de trabalho, observa-se que a gerente parece não perceber a integração da mesma, uma vez que as pessoas são representadas em setores distintos (Figura 3).

Quando a questão é a evolução da inteligência, a experiência de ascensão ao conhecimento nem sempre está assegurada. ${ }^{9}$ Quando os indivíduos vivenciam a adaptação ante a perturbação, não necessariamente ultrapassam as fases de assimilação, acomodação e equilibração que permitem o acesso ao conhecimento. Acontece que eles podem permanecer em qualquer uma destas fases, e, neste sentido, apresentar explicações muitas vezes antagônicas sobre determinados fenômenos, levando a se acreditar que a perturbação não foi resolvida. Inclusive, para alguns, o estancamento em um dos estágios pode revelar que a perturbação sequer chegou a ser reconhecida como tal. Neste caso, importante lembrar, em primeiro lugar, que os saltos epistemológicos não se dão de uma só vez. Em segundo lugar que o indivíduo, muitas vezes, como mecanismo de defesa, opta por privilegiar a idéia de que algo anômalo aconteceu com o método utilizado para a apreensão do objeto de conhecimento, ao invés da idéia de que há lacunas nos seus esquemas de conceitos que impedem uma nova compreensão a seu respeito. Seguindo o mesmo raciocínio, observou-se o processo de racionalização da função gerencial por parte da enfermeira (G5), o qual parece ser utilizado como forma de proteção ou de defesa.

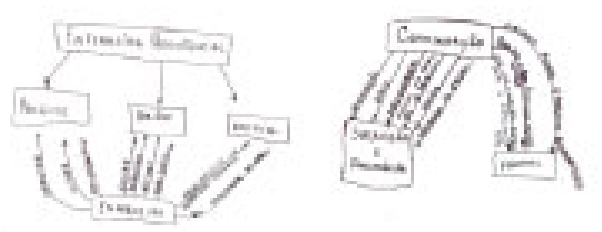

Figura 4 - Representação de G5 sobre o exercício da função gerencial. 
No processo de racionalização há uma organização sistemática de um ato ou prática e uma proteção da gerente, o que sugere a estruturação de sua identidade profissional ou, ainda, a adoção de uma estratégia de dissimulação de uma crise por meio da racionalização (Figura 4). A esse respeito, destaca-se que atualmente, as emoções não são expressas, mas ao contrário, são gerenciadas, assim como as relações, a imagem e até mesmo a identidade. ${ }^{18} \mathrm{O}$ autor acrescenta que “[...] o managerialismo, isto é, o sistema de descrição, de explicação e de interpretação do mundo a partir das categorias da gestão, está profundamente bem instalado na experiência social contemporânea. Ele é, diretamente, o produto de uma sociedade de gestores que busca racionalizar todas as esferas da vida social". 18:17

A crise de identidade também foi expressa por outra gerente (G7), a qual revelou o desejo e a necessidade de ocultar ou proteger seu sentimento profissional ao se referir ao exercício das práticas gerenciais. $\mathrm{Na}$ visão desta gerente (G7) mais uma vez é evidenciado o distanciamento entre as atividades gerenciais e assistenciais. Ademais, a forma esquemática de representação deixa transparecer a divisão social e técnica que caracterizam o processo de trabalho na Saúde e a posição da enfermeira como mediadora das relações interpessoais e responsável pelos resultados institucionais. Por meio da representação de G6 (Figura5), percebe-se a emergência de questões relacionadas às esferas do trabalho e da família.

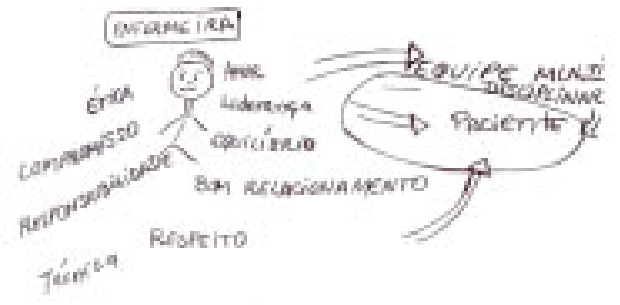

Figura 5 - Representação de G6 sobre o exercício da função gerencial.

A entrevistada parece se expressar como a "rainha do lar", o que se materializa com a presença da coroa em sua cabeça. A segunda parte do desenho reflete a necessidade de atuação da gerente, não somente junto à equipe multidisciplinar, mas também junto ao paciente. Contudo, parece não haver, ainda, uma harmonia em relação à integração desses elementos no exercício da função gerencial, a qual encontra-se em fase de construção. A construção da identidade parece ser a re- alidade vivenciada por G8 (Figura 6) e por G9 (Figura 7). No caso da primeira, sua representação gráfica, reflete a busca de algum tipo de subsídio que lhe proporcione a maior clareza de seu caminho.
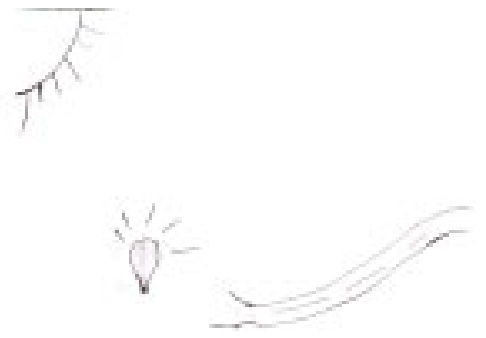

Figura 6 - Representação de G8 sobre o exercício da função gerencial.

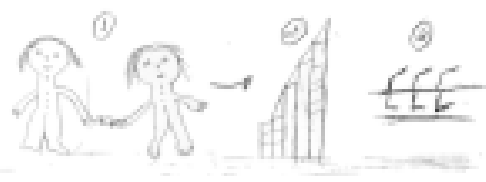

\section{Figura 7 - Representação de G9 sobre o exercício} da função gerencial.

Quanto à segunda, percebe-se uma definição detalhada dos diferentes momentos representados nos desenhos, os quais são identificados por meio de números e em uma seqüência lógica. Também são verificadas barreiras na construção de sua identidade profissional (representação 03, assim nomeada pela própria gerente na Figura 7), bem como a ênfase no relacionamento no exercício de suas atividades, cabendo salientar que os dois personagens poderiam representar a dificuldade de conciliar a função gerencial e as práticas assistenciais.

A representação das enfermeiras-gerente por meio da técnica de desenhos projetivos acerca da fase de transição por que vêm passando possibilitou a legitimação de alguns depoimentos obtidos em suas entrevistas, tais como: eu exerço a função burocrática e além da parte burocrática tem o meu dia-a-dia na parte assistencial. Eu sou uma enfermeira que vive esse dia-a-dia com muito prazer (G6).

Eu procuro conciliar a parte gerencial e assistencial. Por enquanto é tudo muito novo. É um desafio, uma situação nova que me estimula muito, tem me dado muita satisfação (G8).

Tem uma funcionária que me chama de gerenciadora, porque isso pra eles também é novo, é um momento de transição. Tem hora que você é gerente, tem hora que é não sei o que, então tem hora que a cabeça deles...eles sabem que eu sou, mas eles ainda misturam um pouco (G2). 
Os desenhos e depoimentos expressos reforçam a fase de transição vivenciada pelas enfermeiras-gerente, marcada pela adaptação à nova função, tanto por parte das próprias enfermeiras quanto pelos funcionários que com ela partilham o cotidiano de trabalho. A despeito de vivenciarem uma certa indefinição de papéis, as enfermeiras-gerente não manifestam sentimentos de mal-estar e sim a busca de estratégias de conciliação das atividades gerenciais e assistenciais, tendo em vista o caráter de complementaridade que caracteriza essas atividades.

Do ponto de vista do conhecimento, o indivíduo age sobre o objeto a ser conhecido, busca adaptar-se, ou seja, busca o equilíbrio perdido por meio dos processos de assimilação e acomodação. É assim que o objeto exterior vai sendo substituído por reconstruções endógenas do indivíduo, resultando em estruturas de conhecimento cada vez mais complexas.

\section{Equilibração: regendo a orquestra}

A fase de equilíbrio ou de estabilidade também pode ser evidenciada entre as enfermeiras-gerente (G3) e foi representada por meio de sua centralidade em relação à equipe multiprofissional, refletindo a importância da enfermeira na viabilização das relações interpessoais e na gestão dos recursos envolvidos na prestação do cuidado ao paciente. Nessa perspectiva, destaca-se a posição nuclear da enfermeira-gerente na equipe de saúde, a qual é influenciada pelo seu processo de formação, principalmente na graduação, o qual lhe confere atributos imprescindíveis para o exercício da gerência. Tais atributos estão ligados à capacidade de visualizar a organização em sua totalidade, o que significa possuir uma visão global da organização considerando a interrelação entre os diferentes recursos e setores que a compõe. A capacidade de liderar a equipe e atuar de forma efetiva na mediação das relações e dos conflitos também é um diferencial que tem contribuído de forma decisiva para a inserção da enfermeira na gestão institucional.

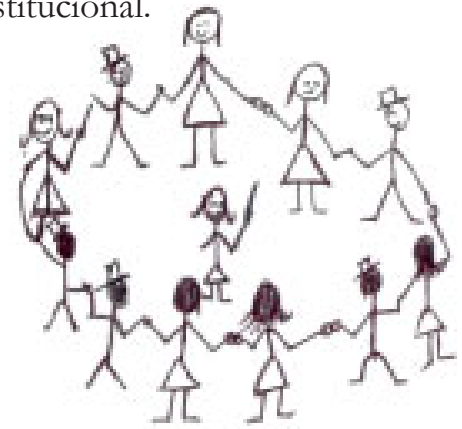

Figura 8 - Representação de G3 sobre o exercício da função gerencial.
Ainda em relação à representação apresentada (Figura 8), há que se chamar à atenção para a presença de homens e mulheres, em faixas etárias diversificadas e em diferentes posições hierárquicas na organização e o desempenho de um papel triplo, ou seja, a gerente assume a função de movimentar o grupo com o auxílio da "batuta"; situa-se no centro, revelando uma certa exposição em relação ao grupo $\mathrm{e}$, ao mesmo tempo, tendo que responder às expectativas do mesmo. A gerente é também, observada e controlada pelo grupo.

Utilizando os conceitos relacionados à estruturação do conhecimento pelo indivíduo, sabe-se que após percorrer o caminho constituído pelos processos de assimilação e acomodação, o indivíduo ascende de um determinado nível de conhecimento para outro nível superior. Trata-se do processo de equilibração, segundo o qual o indivíduo se encontra pronto para novas "perturbações" no seu sistema cognitivo a partir da incorporação do novo conhecimento na sua estrutura conceitual.

Dito de outra forma, o sistema se reequilibra por um processo de construção compensatória que pode levar a um equilíbrio melhor que o anterior. $\mathrm{Na}$ reequilibração majorante podem até ocorrer construções compensatórias, mas elas conduzem a um equilíbrio instável. ${ }^{9} \mathrm{O}$ aumento de conhecimento só é efetivo quando o sistema cognitivo absorve as perturbações, atingindo um novo estado de equilíbrio diferente e superior ao anterior, uma vez que incorporou a perturbação como algo dedutível ou previsível. Nesta fase, os conflitos são em parte ou integralmente resolvidos e as lacunas são preenchidas por reforços e acomodação de novos conceitos.

Ultrapassada a fase da equilibração, espera-se que as idéias mudem e se desloquem, pois a experiência com o saber implica formulações e alterações no saber sobre si próprio, sobre o outro, sobre o mundo social e o mundo profissional. Observa-se que as informações são reelaboradas pelos indivíduos, assumindo novos sentidos. Em última instância, verifica-se que os indivíduos conseguem pensar o que ainda não haviam pensado, atribuindo novos significados às representações elaboradas sobre si e sobre a sua realidade.

Compreender como se dá o processo de conhecer e sua relação com a construção da identidade é fundamental para a formulação de processos educacionais que promovam espaços reflexivos às enfermeiras-gerente para o reconhecimento das diferentes dimensões do exercício da gerência que permita o pro- 
cesso de renovação e criação da identidade no contexto das relações de trabalho.

É por meio da ação e refletindo sobre ela que as enfermeiras-gerente podem ultrapassar os diferentes estágios identitários chegando a um equilíbrio que, sabe-se instável. A educação neste contexto é compreendida como espaço de reflexão sobre o próprio trabalho incluindo a história de vida, as experiências e os contextos que antecederam a escolha da profissão, bem como os momentos de exercício profissional ao longo da carreira, as condições e os contextos nas quais tais momentos se efetivam.

Isso ressalta a importância do debate teórico, das melhorias e adequações não só na formação inicial dos enfermeiros, mas também nas oportunidades de continuidade e aprofundamento dessa formação ao longo da vida profissional.

\section{REFLEXÕES FINAIS}

Retomando o objetivo deste artigo, observou-se que as enfermeiras-gerente situam-se em diferentes estágios identitários em relação à função gerencial (transição, crise e estabilidade). Uma provável explicação para o fato de a maioria se encontrar na fase de transição deve-se à sua recente inserção na gerência de organizações de saúde, ressaltando-se que nos hospitais essa tendência vem sendo observada, sobretudo, na última década.

Importante sublinhar que no cenário atual, onde são notórias as mudanças na concepção de conhecimento e sujeito, a noção de identidade e de formação identitária deve ser problematizada a fim de que possa ser vista numa perspectiva de renovação e criação. $\mathrm{O}$ que se quer questionar aqui é a idéia de permanência, de imutabilidade, que reside no âmago da idéia de identidade. O que se defende é a substituição da idéia de permanência associada à dimensão identitária pela idéia de contínua reconstrução de identidades, o que remete à reflexão acerca do caráter relacional e contingente das identidades de indivíduos e grupos.

Em face dos resultados deste estudo, pode ser reforçado o questionamento sobre as representações do sujeito moderno, ancoradas na subjetividade individualizada, levando os indivíduos a se representarem como constituídos por uma identidade única, imutável, indivisível e marcada por um rol de características definidoras.
Ressalta-se, ainda, a tendência cada vez mais marcante de configuração da gestão hospitalar como um campo instigante de investigação, considerandose que as identidades sociais e profissionais são resultados de construções sociais alicerçadas nas trajetórias individuais, nos processos de construção do conhecimento e nas relações de trabalho. Refletem, portanto, configurações identitárias específicas do momento histórico e de produção de cada sociedade, reafirmando a natureza contingencial e dinâmica da identidade, o que a caracteriza como um eterno "vir-a-ser", transcendendo o cotidiano de cada um nas possibilidades múltiplas de crise, transição e estabilidade.

\section{REFERÊNCIAS}

1 Dubar C. A socialização: construção das identidades sociais e profissionais. 2a ed. Porto (Portugal): Editora LDA; 1997.

2 Castells M. O poder da identidade. 2a ed. São Paulo: Paz e Terra; 2000.

3 Jacques MG. Psicologia social contemporânea. 5a ed. Petrópolis (RJ): Vozes; 2001.

4 Ciampa AC. Identidade. In: Lane STM, Codo W, organizadores. Psicologia social: o homem em movimento. $13 \mathrm{a}$ ed. São Paulo: Brasiliense; 2001. p.5875.

5 James W. The letters. Boston: Atlantic Monthly Press; 1920.

6 Mead G. Mind, self and society. Chicago: University of Chicago Press; 1934

7 Araújo Netto LFS, Ramos FRS. O espelho da identidade no cotidiano da(o) enfermeira(o). Texto Contexto Enferm.2002 Jan-Abr; 11 (1): 244-64.

8 Piaget J. A epistemologia genética; sabedoria e ilusões da filosofia; problemas de psicologia genética. 2a ed. São Paulo: Abril Cultural; 1983.

9 Piaget J. O nascimento da inteligência na criança. 2a ed. Rio de Janeiro: Aahar Editores/MEC; 1975.

10 Turato ER. Tratado de metodologia da pesquisa clínicoqualitativa: construção teórico-epistemológica, discussão comparada e aplicação nas áreas de saúde e humanas. Petrópolis (RJ): Vozes; 2003.

11 Minayo MCS. O desafio do conhecimento: pesquisa qualitativa em saúde. 8a ed. São Paulo: Hucitec; 2004.

12 Laurenção O. Testes projetivos gráficos no diagnóstico psicológico. São Paulo: EPU/Editora Pedagógica Universitária; 1984. 
13 Zuboff S. In the age smart machine-the future of work and power. Washington(USA): United States of America, Basic Books; 1988.

14 Silva JR, Vergara SC. Análise comparativa acerca da utilização de desenhos na pesquisa sobre a criação do sentido da mudança organizacional. Organização Sociedade. 2002 Jan-Abr; 9 (23): 159-69.

15 Caldas MP, Tonelli MJ. Casamento, estupro ou dormindo com o inimigo? Interpretando imagens e representações dos sobreviventes de fusões e aquisições. Organização Sociedade. 2002 Jan-Abr; 9 (23): 171-86.
16 Bardin L. Análise de conteúdo. Lisboa: Edições 70; 1977.

17 Melo MCOL. Estratégias do trabalhador informático nas relações de trabalho [tese]. Belo Horizonte: Faculdade de Ciências Econômicas/Universidade Federal de Minas Gerais; 1991.

18 Chanlat JF. Ciências sociais e management: reconciliando o econômico e o social. São Paulo: Atlas; 2000. 